\title{
EDUKASI KESEHATAN PRENATAL YOGA PADA IBU HAMIL TRIMESTER III DI PUSKESMAS PUTRI AYU KOTA JAMBI
}

\author{
Nurbaiti \\ D III kebidanan Sekolah Tinggi Ilmu Kesehatan Baiturrahim Jambi \\ Email.nbaiti812@gmail.com
}

\begin{abstract}
Pregnancy is a natural event experienced by a mother. During pregnancy, the mother will experience physical and mental changes. Changes that occur even provide discomfort for mothers such as back pain, aches in the legs, anxiety, and so forth. One treatment for pregnancy is exercise. pregnant women who exercise regularly, report lower levels of discomfort during the pregnancy process, and heal faster than those who do not exercise during pregnanc. For those who are active in sports, require a little intervention Sectio Caesarea (SC) and can shorten the first and second stages of labor compared with those who do not exercise. One of the sports is prenatal yoga. Putri Ayu Health Center is one of the Health Centers that has provided pregnancy exercise services but has never provided prenatal yoga services in pregnancy, on the grounds that there are no trained personnel at the Puskesmas. Community Service Activities carried out at the Putri Ayu Health Center, Jambi City, time of implementation in June 2019. The target is pregnant women, especially TM III with survey approach methods, lectures, discussions, demonstrations / simulations. The results obtained by mothers are able to understand about prenatal yoga and its benefits and can do prenatal yoga routinely. It is suggested to the puskesmas to facilitate prenatal yoga.
\end{abstract}

Keywords: education, pregnancy, yoga

\begin{abstract}
ABSTRAK
Kehamilan merupakan peristiwa alamiah yang dialami oleh seorang ibu. Pada masa kehamilan, ibu akan mengalami perubahan fisik maupun mental. Perubahan yang terjadi bahkan memberikan ketidaknyamanan bagi ibu seperti sakit pada punggung, pegal pada kaki, cemas, dan lain sebagainya. Salah satu perawatan kehamilan adalah dengan olahraga. ibu hamil yang berolahraga secara teratur, tingkat laporan ketidaknyamanan selama proses kehamilan lebih rendah, dan penyembuhan lebih cepat dibandingkan dengan yang tidak berolahraga selama kehamilan. Bagi yang giat berolahraga, membutuhkan sedikit intervensi Sectio Caesarea (SC) dan dapat memperpendek kala I dan kala II persalinan dibandingkan dengan yang tidak berolahraga. Salah satu Olahraganya adalah dengan prenatal yoga. Puskesmas Putri Ayu adalah salah satu Puskesmas yang sudah memberikan pelayanan senam hamil tapi belum pernah memberikan pelayanan prenatal yoga dalam kehamilan, dengan alasan belum ada tenaga yang terlatih di Puskesmas tersebut. Kegiatan Pengabdian masyarakat dilaksanakan di Puskesmas Putri Ayu Kota Jambi, waktu pelakasann pada bulan Juni 2019. Sasaran adalah ibu hamil khususnya Trimester III dengan metode pendekatan survei, ceramah, diskusi, demonstrasi/simulasi. Hasil yang diproleh ibu-ibu mampu memahami tentang prenatal yoga dan manfaat serta dapat melakukan prenatal yoga secara rutin. Di sarankan kepada puskesmas agar dapat memfasilitasi untuk prenatal yoga.
\end{abstract}

Kata Kunci: kehamilan, pendidikan, yoga 


\section{PENDAHULUAN}

Dunia kembali merumuskan komitmen global dalam bidang kesehatan untuk 15 tahun ke depan. Kali ini diberi nama Sustainable Development Goals (SGDs) yang akan dicapai sampai dengan tahun 2030.SDGs atau tujuan pembangunan berkelanjutan ini hadir menggantikan Millenium Development Goals (MDGs) yang disepakati oleh 198 negara di tahun 2000 (Kemenkes RI, 2016).

Kehamilan merupakan peristiwa alamiah yang dialami oleh seorang ibu. Namun bagi ibu yang hamil pertama kali, hal ini sering dianggap sebagai peristiwa yang mencemaskan. Banyak ibu hamil akan mengurangi pekerjaan yang membutuhkan tenaga sehingga otot-otot dan sendi dalam tubuh semakin tidak efisien yang berakibat tidak elastisnya otot dan sendi. Pada masa kehamilan, ibu akan mengalami perubahan fisik maupun mental. Perubahan yang terjadi bahkan memberikan ketidaknyamanan bagi ibu seperti sakit pada punggung, pegal pada kaki, cemas, dan lain sebagainya. Ibu hamil sangat membutuhkan tubuh yang sehat dan bugar, serta pikiran yang rileks, dimana kondisi ini dapat diperoleh dengan mengupayakan pola makan yang teratur, istirahat yang cukup dan olah tubuh. Untuk memelihara kesehatan ibu hamil perlu dilakukan perawatan kehamilan. Salah satu perawatan kehamilan adalah dengan olahraga. Ibu hamil yang berolahraga secara teratur, tingkat laporan ketidaknyamanan selama proses kehamilan lebih rendah, dan penyembuhan lebih cepat dibandingkan dengan yang tidak berolahraga selama kehamilan. Bagi yang giat berolahraga, membutuhkan sedikit intervensi Sectio Caesarea (SC) dan dapat memperpendek kala I dan kala II persalinan dibandingkan dengan yang tidak berolahraga.

Salah satu Olahraganya adalah dengan berlatih senam yoga, Yoga adalah jenis olah tubuh, pikiran dan mental yang sangat membantu ibu hamil dalam melenturkan persendian, termasuk menenangkan pikiran Faktor yang mempengaruhi ibu hamil mengikuti kelas prenatal yoga adalah (minat ibu hamil dalam mengikuti kelas prenatal yoga) antara lain adalah Faktor dari dalam adalah ; Kepercayaan diri, Kepribadian, Perasaan, persepsi. Dan Faktor dari luar Jenis kelamin, Tingkat Pengetahuan, Tingkat pendidikan

Puskesmas Putri Ayu adalah salah satu Puskesmas yang sudah memberikan pelayanan senam hamil tapi belum pernah memberikan pelayanan prenatal yoga dalam kehamilan, dengan alasan belum ada tenaga yang terlatih karena tidak adanya pelayanan prenatal yoga pada ibu hamil di Puskesmas Putri Ayu sehingga pengetahuan ibu masih rendah maka dari itu solusi yang di tawarkan adalah memberikan pendidikan kesehatan mengenai prenatal yoga pada ibu hamil di Puskesmas Putri Ayu Kota Jambi yang bertujuan untuk meningkatkan pengetahuan dan melatih ibu dalam melakukan prenatal yoga sehingga ibu dapat mempersiapkan keadaan fisik dan psikologi untuk persalinan normal.

\section{TARGET DAN LUARAN}

1. Target

Kegiatan pengabdian kepada masyarakat ini memiliki :

a. Ibu hamil khususnya trimester III

b. Petugas kesehatan

c. Ibu hamil memiliki pengetahuan tentang prenatal yoga $(>95 \%)$

2. Luaran

Adapun luaran dari kegiatan pengabdian ini selain pablikasi pada jurnal ilmiah dan di harapkan ibu dapat memahami tentang manfaat prenatalyoga dan mengikuti kelas yoga untuk mempersiapkan keadaan fisik dan psikologisnya untuk persalinan normal

\section{METODE PELAKSANAAN}

Kegiatan pengabdian kepada masyarakat ini di laksanakan pada bulan Juni 2019 dengan dibantu oleh beberapa orang mahasiswa Stikes Baiturrahim Jambi. Sasaran dalam kegiatan ini ibu hamil khsusnya ibu hamil Trimester III di Puskesmas Putri Ayu Kota Jambi berjumlah 32 orang dengan metode ceramah, Tanya jawab, diskusi dan demonstrasi, media yang di gunakan lieflet, leptop, speaker, infokus, pengeras suara.

Tahapan yang akan dilaksanakan dalam kegiatan promosi kesehatan terkait Edukasi 
Kesehatan Prenatal Yoga Pada Ibu Hamil Trimester III Di Puskesmas Putri Ayu Kota Jambi:

Persiapan

a. Sosialisasi : pertemuan kepada kepala puskesmas, kepala ruangan KIA

b. Melakukan tertib administrai di Puskesmas Putri Ayu

Pelaksanaan

a. Melakukan pre test (mengali penetahuan pemahamn ibu hamil tentang prenatal yoga)

b. Memberikan pendidikan kesehatan tentang prenatal yoga, manfaat yoga untuk kehamilan, dan untuk persiapan persalinan.

c. Melakukan demonstrasi latihan prenatal yoga

d. Melakukan evaluasi

\section{HASIL PEMBAHASAN}

Kegiatan pengabdian kepada masyarakat ini bertujuan agar ibu hamil memahami tentang prenatal yoga, tujuan, manfaat dan kontra indikasi dalam melakukan yoga pada kegiatan pengabdian masyarakat ini tim juga melakukan demostrasi prenatal yoga. kegiatan ini berlangsung kurang lebih 30 menit dan terlaksana dengan tertib dan lancer dan mendapatkan sambutan yang baik oleh Puskesmas Putri Ayu Kota Jambi.

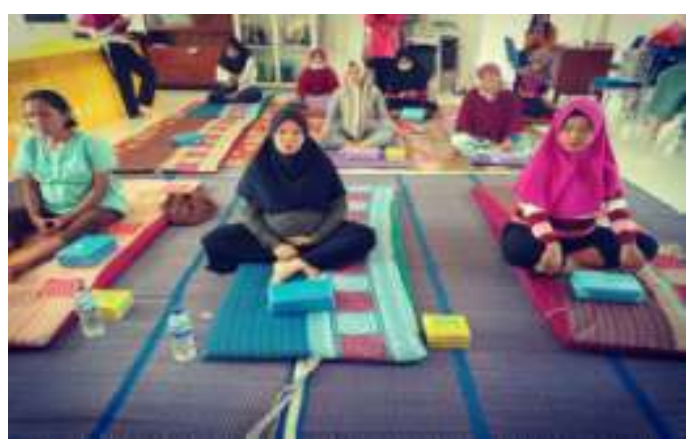

Gambar 1. Melakukan pendidikan kesehatan berupa penyuluhan tentang prenatal yoga pada ibu hamil di Pueskesmas Putri Ayu Kota Jambi

Yoga adalah jenis olah tubuh, pikiran dan mental yang sangat membantu ibu hamil dalam melenturkan persendian, termasuk menenangkan pikiran Faktor yang mempengaruhi ibu hamil mengikuti kelas prenatal yoga adalah (minat ibu hamil dalam mengikuti kelas prenatal yoga) antara lain adalah Faktor dari dalam adalah ; Kepercayaan diri, Kepribadian, Perasaan, persepsi. Dan Faktor dari luar Jenis kelamin, Tingkat Pengetahuan, Tingkat pendidikan

Tujuan yoga yaitu Secara umum untuk memberikan dorongan serta latihan secara jasmani dan rohami dari ibu agar siap menghadapi persalinan manfaatnya dapat merelaksasi, mengurangi rasa sakit, tidur lebih berkualitas, meguatkan otot, mempermudah proses persalinan, dan mengurangi rasa takut. Sedangkan kontraindikasinya Ibu hamil dengan riwayat keguguran, Ibu hamil dengan preeklamsi, placenta previa totalis, Ibu hamil dengan riwayat perdarahan selama kehamilan dan Ibu hamil dengan riwayat serviks inkompeten (mulut rahim lemah)

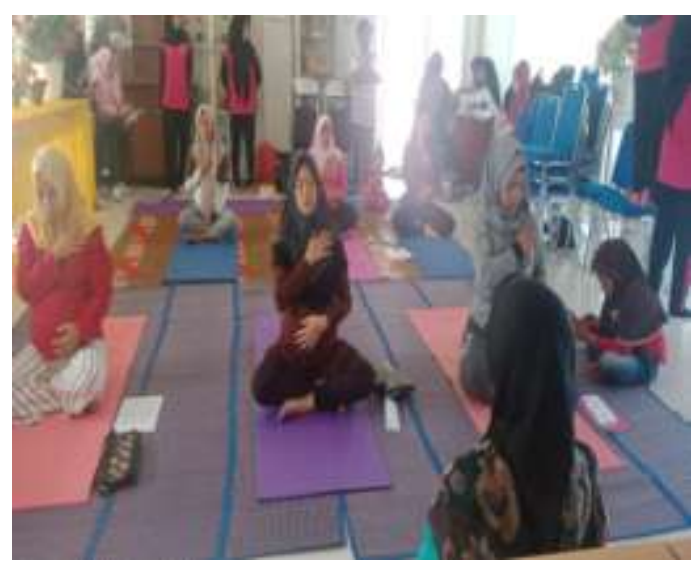

Gambar 2. Melakukan latihan prenatal yoga pada ibu hamil di Puskesmas Putri Ayu Kota Jambi

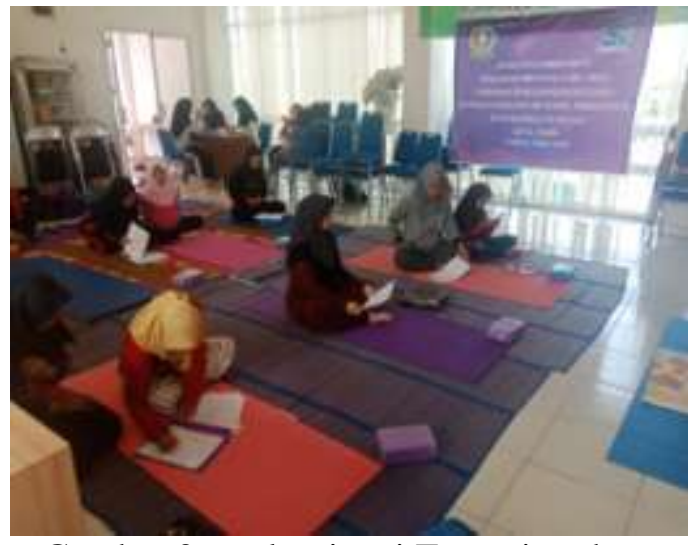

Gambar 3. evaluasi sesi Tanya jawab untuk mengetahui sejauh mana pemahaman ibu -ibu tentang prenatal yoga 


\section{KESIMPULAN}

\section{Kesimpulan}

Prenatal yoga dapat dilakukan melalui gerakan tubuh yang disertai tehknik pegaturan nafas dan pemusatan konsentrasi, fisik akan lebih sehat, bugar, kuat, emosi akan lebih seimbang. Prenatal yoga dapat mengurangi rasa sakit, cemas, rasa takut, menguatkan otot, tidur lebih nyaman dan mempermudah proses persalianan prenatal yoga tidak boleh di lakukan oleh ibu yang mempunyai riwayat keguguran, ibu hamil dengan preeklamsi, plancenta previa dan riwayat perdarahan selama hamil

Dari kegiatan pengabdian kepada masyarakat. Ibu mengerti dan mamahami tentang prenatal yoga dan manfaat untuk kehamilannya sehingga ibu dapat menghadapi persalinan dengan nyaman dan ibu ingin melakukan yoga secara rutin jika ada pelayanan di puskesmas atau melakukan yoga mandiri

\section{Saran}

Di harapkan kepada tenaga puskesmas khususnya bagian KIA agar dapat memberikan pelayanan prenatal yoga kepada ibu hamil di Puskesmas Putri Ayu Kota Jambi.

\section{UCAPAN TERIMAKASIH}

Tim pengabdian masyarakat mengucapkan terimaksih yang sebesarbesarnya kepada Stikes Baiturrahm Jambi atas dana dan fasilitas serta surat izin dalam melakukan pengabdian masyarakat ini dan juga kepada Kepala Puskesmas Putri Ayu dan Kepala ruangan KIA yang telah memberikan izin tempat dan membantu dalam kegiatan pengabdian masyarakat ini sehingga kegiatan ini berjalan dengan lancar.

\section{DAFTAR PUSTAKA}

Asrinah dkk. 2010. Konsep kebidanan. Yogyakarta. Graha ilmu

Astuti Puji. 2012. Asuhan kebidanan masa kehamilan. Yogyakarta. Graha ilmu

Bobak, Lowdermilk, Jensen, 2004, Buku Ajar Keperawatan Maternitas/
Maternity Nursing. Alih Bahasa

Maria A. Wijayanti. Peter I. Anugerah, edisi 4. Jakarta : EGC

Notoatmodjo,Soekidjo, 2012. Promosi Kesehatan dan Ilmu Perilaku. PT Rineka Cipta. Jakarta.

Purwanto. 2011 Instrummen penelitian soaial dan pendidikan. Yogyakarta. Pustaka Pelajar.

Tim Trainner renatal Gentle Yoga.(2016). Modul prenatal gentle Yoga.Kristara.

Ummi. (2010). Asuhan kebidanan pada kehamilan fisiologis. Jakarta: Salemba Medika 